Vantage: Journal of Thematic Analysis

ISSN: 2582-7391

A Multidisciplinary Publication of Centre for Research,

Maitreyi College, University of Delhi

April 2020, Volume 1, Issue 1

Original Research Article

\title{
Synthesis of Iron Oxide Nanoparticles and its Application for Oil- Water Separation
}

\author{
Mansi Dhingra*, Parul Yadav, Savvi Mishra, Vishakha Dwivedi, Komal, Anupriya and \\ Sonam \\ Department of Physics, Maitreyi College, University of Delhi, New Delhi-110021, India \\ *Correspondence: mansidhingra84@gmail.com
}

\begin{abstract}
Magnetic nanoparticles have been explored extensively for their applications in day to day life. Among their various uses like magnetic data storage and biomedical applications, they have remained a field of interest for researchers. The well known magnetic nanoparticles are iron oxide nanoparticles. In this work, iron oxide nanoparticles are prepared by self sustained combustion technique. Ferric nitrate $\left(\mathrm{Fe}\left(\mathrm{NO}_{3}\right)_{3} \cdot 9 \mathrm{H}_{2} \mathrm{O}\right)$ was used as a precursor and ethylene glycol as a fuel. Solution was heated at $120^{\circ} \mathrm{C}$. After being preheated to the boiling point of ethylene glycol and its evaporation, the solution self-ignites and the temperature rises rapidly to values as high as $1500^{\circ} \mathrm{C}$. Magnetic properties of $\mathrm{Fe}_{2} \mathrm{O}_{3}$ are studied using vibrating sample magnetometer (VSM). The magnetic properties are utilized for separation of oil from oil-water mixture.
\end{abstract}

Keywords: Magnetic nanoparticles, Self combustion, oil separation

\section{INTRODUCTION}

Pollution can be understood as introduction of poisonous substances into the environment. There are different forms of pollution and one of them is water pollution. Water is a crucial element of nature as every living being, directly or indirectly, depends on water. Oil spills cause irreparable damage to the water which is being discharged into the environment. The oil can be separated from water by mechanical extraction with sorbents which is considered to be one of the most economical and efficient methods (iotobf document guides).

The introduction of nanotechnology played a major role in the growth, research and development of such sorbent materials. Nanostructured materials possess high surface to volume ratio. Since, adsorption is a surface phenomenon, nanostructured particles used as adsorbents will react more with the oil molecules. 
Magnetised metal oxide based on nanostructure, such as iron oxide are majorly used for oil water separation as the sorbent material of oils due to their selective behavior, larger porosity, effective surface area, high adsorption coefficient, super hydrophobicity and magnetic properties. Sorbent material is hydrophobic (Poole \& Owens, 2003; Aruna \& Mukasyan, 2008; Sharma et al., 2014). The hydrophobicity helps in entagling of oil droplets with nanoparticles, the complex so formed is further extracted from water. The reported studies suggest that the functional groups present on the surface of magnetic nanoparticles provide a large number of active site as well as aqueous stability, so it has high adsorption capacity (Simonsen et al., 2018). The focus has been made on the synthesis of iron oxide particles as it can be crystalline in different polymorphic phases which include hematite, maghemite and magmetite. Wet chemical route is used in synthesis of nanoparticles of iron oxide. The $\mathrm{Fe}_{2} \mathrm{O}_{3}$ nanoparticles have been prepared by self-combustion method using ferric nitrate as the precursor and its mixture in ethylene glycol (Palchoudhury et al., 2014). The synthesized nanoparticles show magnetic properties. Due to these magnetic properties they can be mixed in oil-water solution and then can be separated through a strong magnet.

\section{MATERIALS AND METHODS}

\subsection{Materials}

For the preparation of $\mathrm{Fe}_{2} \mathrm{O}_{3}$ nanoparticles, solid ferric nitrate and ethylene glycol were purchased from chemical dealer. All the chemicals were used in the same form as received, without any further purification process. Mortar-pestle, magnetic beads, magnetic stirrer, heater and two types of oils were purchased from market. Solid ferric nitrate was taken and converted into fine powder using mortar pestle.

\subsection{Method}

$16.16 \mathrm{~g}$ of powdered ferric nitrate was taken and dissolved in $500 \mathrm{ml}$ of ethylene glycol to make 0.8 M solution. Solution so obtained was stirred using magnetic stirrer for thirty minutes at room temperature. Once a homogenous solution was obtained the magnetic bead was taken out and pure solution was heated for about half an hour at $225^{\circ} \mathrm{C}$. It was observed that as the solution started drying, the lumps of red powder started appearing which got self ignited. The self ignition was evident from the orange colored glow within the red powder. Combustion begins when the local temperature increases rapidly and red powder starts converting into crystallites (Ali et al., 2016). The crystallites so obtained were taken out from beaker and further crushed using mortal pestle as shown in Figure 1. 

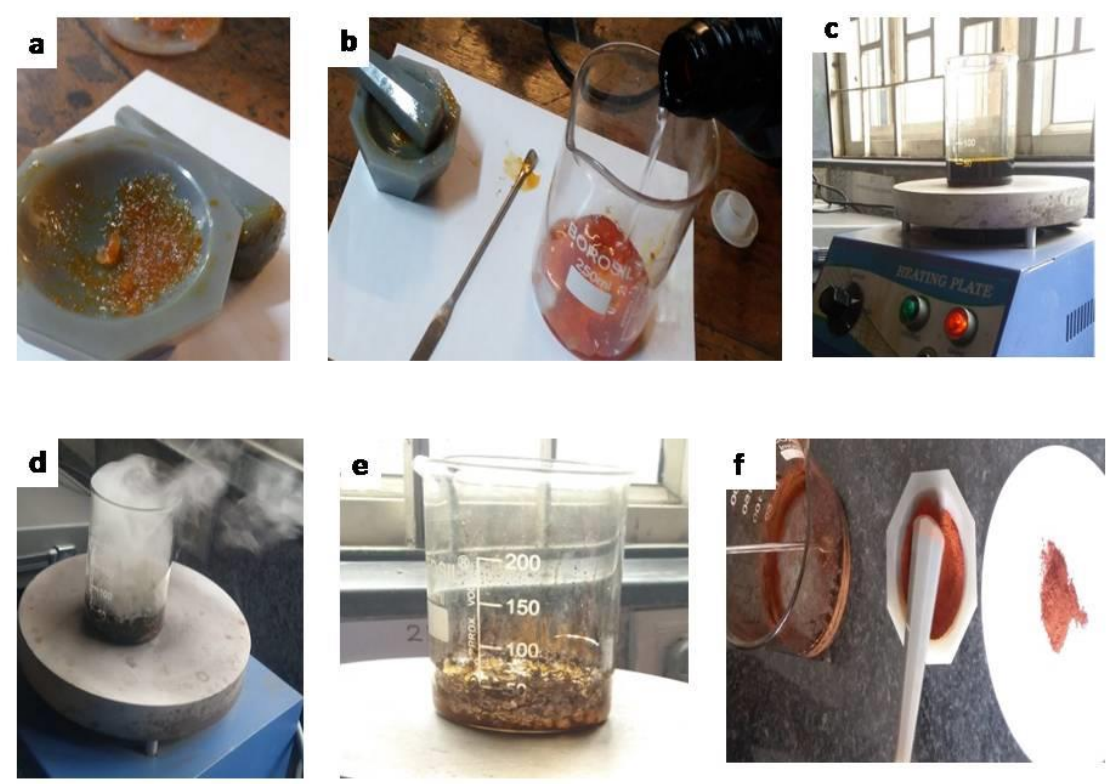

Figure 1 (a - f): Images clicked at different times during synthesis of nanoparticles

\section{RESULTS \& DISCUSSION}

Reddish brown coloured powder was formed which showed the synthesis of iron oxide nanopaticles which were affected and attracted by bar magnet. A small amount of powder was kept on top of a paper and a bar magnet was made to rotate about it from below. The powder immediately got stuck near the magnetic lines of forces coming from the permanent magnet.

\subsection{Magnetic Measurements}

In order to get an insight of the magnetic behavior the magnetic measurements were done using vibrating sample magnetometer (VSM). Hysteresis curve, thus obtained, is shown in Figure 2. It was observed that the obtained nanoparticles were soft ferromagnetic in nature with a saturation magnetization of $28 \mathrm{emu}$ per gram. However, the coercivity was very low making the loop look thin. This is characteristic of iron oxide nanopowder with a gamma phase (Dhara et al., 1993).

\subsection{Oil separation from the mixture}

Two types of oils, namely mustard oil and machine lubricant oil, were mixed with water in different petridishes.

Separation with mustard oil: Small amount of iron oxide nanoparticles were dispersed in this mixture. The oil molecules got attached to the magnetic nanoparticles. However, it was observed that the nanoparticles had a bit low adsorption. Also, the nanoparticles got easily 
attracted towards the bar magnet, so it was easier to separate oil from oil-water mixture as shown in Figure 3.

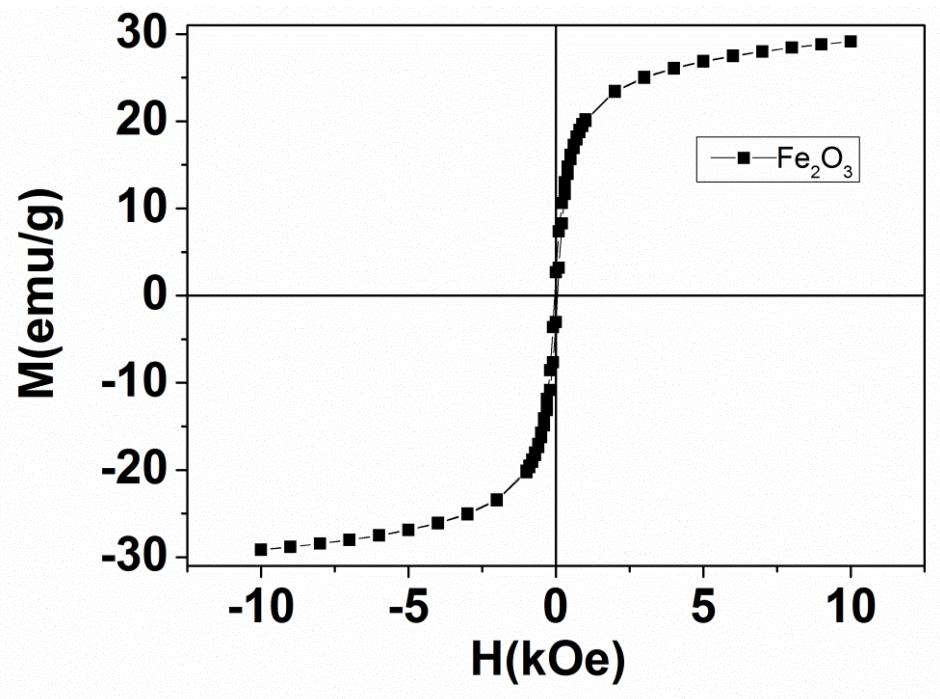

Figure 2: Hysteresis curve for iron oxide nanoparticles
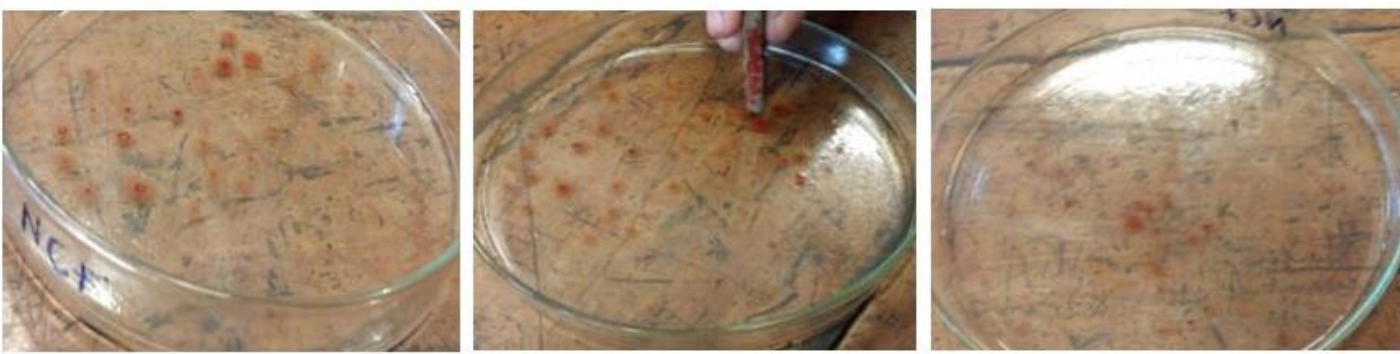

Figure 3: Extraction of mustard oil from oil-water mixture using iron oxide nanoparticles

Separation with machine lubricating oil: With this oil, the amount of nanoparticles to be dispersed was more as compared to mustard oil. It also got attracted by the bar magnet. Figure 4 shows the step by step process of extraction of oil.
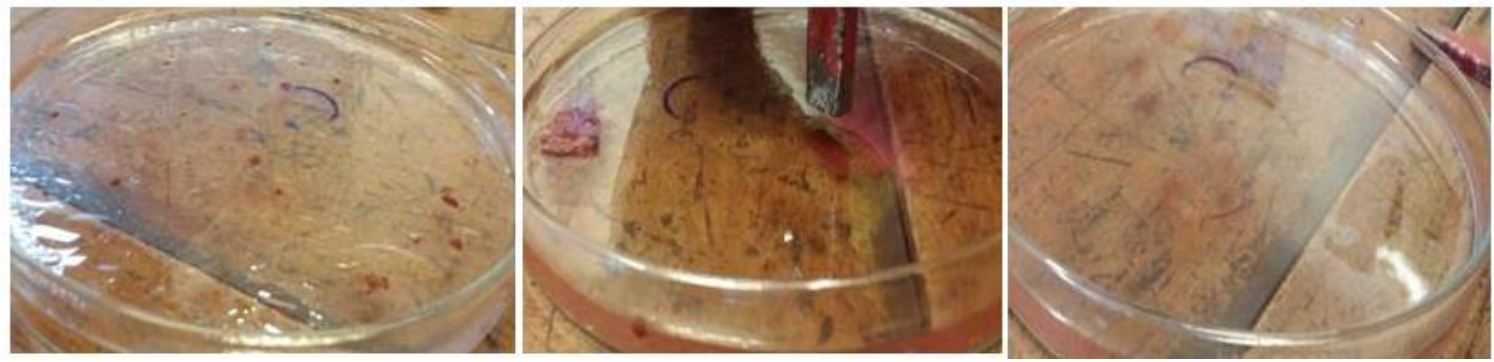

Figure 4: Extraction of lubricant oil from oil-water mixture using iron oxide nanoparticles

\section{CONCLUSION}

Our study demonstrated the preparation of iron oxide nanoparticles by wet chemical route method. The magnetic measurement of Iron Oxide nanoparticles was carried out using 
Vibrating Sample Magnetometer. The resulting nanoparticles showed magnetic properties. Thus, the magnetic properties shown by iron oxide were used to separate oil from oil-water mixture with the help of bar magnet. The amount of magnetic iron oxide nanoparticles could be optimised for separation of oil from oil-water mixture.

\section{CONFLICT OF INTEREST}

Authors declare that there is no conflict of interest regarding this research article.

\section{SOURCE OF FUNDING}

The financial support for the procurement of chemicals, consumables etc. was provided by Maitreyi College, University of Delhi.

\section{ACKNOWLEDGEMENT}

The authors would like to acknowledge Maitreyi College, University of Delhi for providing the infrastructure and basic facility to conduct experiments. Authors also would like to thank University Science and Instrumentation Centre (USIC) and University of Delhi for VSM studies.

\section{REFERENCES}

Ali, A, Zafar, H., Zia, M., Haq, I.U.,Phull, A.R., Ali, J.S. \& Hussain, A. (2016). Synthesis, characterization, applications and challenges of iron oxide nanoparticles. Nanotechnology Science and Applications, 9: 49-67. DOI: https:// 10.2147/NSA.S99986

Aruna, T. \& Mukasyan, A.S. (2008). Combustion Synthesis. Current Opinion in Solid State and Materials Science, 1244-1250.

Dhara, S., Rastogi, A.C. \& Das, B.K. (1993). Direct deposition of highly coercive gamma iron oxide thin films for magnetic recording. Journal of Applied Physics, 74, 7019-24. https://doi.org/10.1063/1.355062

International Tanker Owners Pollution Federation Ltd. (ITOPF) data. Retrieved from: https://www.itopf.org/knowledge-resources/documents guides/economic-effects/

Palchoudhury, S. \& Lead, J.R. (2014). A Facile and Cost-Effective Method for Separation of Oil-Water Mixtures Using Polymer-Coated Iron Oxide Nanoparticles. 
Environmental Science \& Technology, 48 (24), 14558-14563. DOI: https://doi.org/10.1021/es5037755

Poole, C.P., Frank, Jr. \& Owens, J. Introduction to Nanotechnology, John Wiley \& Sons, Inc., Hoboken, New Jersey.

Sharma, B., Joshi, M. \& Singh, R.P. (2014). A Novel of Synthesis of Iron Oxide Nanoparticles for Separation of Water-Oil, Water-Diesel, Water-Petrol. In: Jain V., Verma A. (eds) Physics of Semiconductor Devices. Environmental Science and Engineering. Springer, Cham, 565-567, DOI: https://doi.org/10.1007/978-3-319$\underline{03002-9 \_142}$

Simonsen, G., Strand, M. \& Øye, G. (2018). Potential applications of magnetic nanoparticles within separation in the petroleum industry. Journal of Petroleum Science and Engineering, 165, 488-495. DOI: 10.1016/j.petrol.2018.02.048

How to cite this article: Dhingra, M., Yadav, P., Mishra, S., Dwivedi, V., Komal, Anupriya \& Sonam (2020). Synthesis of Iron Oxide Nanoparticles and its Application for Oil-Water Separation. Vantage: Journal of Thematic Analysis, 1(1), 41-46.

DOI: https://doi.org/10.52253/vjta.2020.v01i01.05

(C) The Author(s) 2020.

This work is licensed under a Creative Commons Attribution 4.0 International License which permits its use, distribution and reproduction in any medium, provided the original work is cited. 